\title{
PEMAKNAAN RASISME DALAM FILM (ANALISIS RESEPSI FILM GET OUT)
}

\author{
Adlina Ghassani \\ Catur Nugroho \\ Jurusan Ilmu Komunikasi, Fakultas Komunikasi dan Bisnis, Universitas Telkom, Bandung \\ Email: ghassaniadlina@gmail.com; mas_pires@yahoo.com \\ Submitted: Aug 20, 2018; Reviewed: Aug 20, 2018; Accepted: Aug 24, 2018

\begin{abstract}
Movie is one form of mass communication media which often enjoyed by people. The movie Get Out that is directed by Jordan Peele shows about how is the act of white people discrimination towards black people. This research uses the qualitative method with descriptive type and uses Stuart Hall's reception analysis approach. Reception analysis views the active audiences which are the viewers and readers to produce and reproduce the meaning in an impression of a media. The purpose of this research is to describe audiences' interpretation and to know the position of the audiences according to Stuart Hall's three readership position towards the movie Get Out that shows racism. This research uses paradigm of constructivism. The result of this research shows that audiences meaning of the movie Get Out towards the four informants generates different meaning and out of seven scene analysis units studied, the audiences' position in their acceptance of the racism in the movie Get Out is dominated by oppositional position. There are also some informant that are in dominant hegemonic position. Where in each scene contains different racism material.
\end{abstract}

Keywords: Communication; Reception Analysis; Film

\section{PENDAHULUAN}

Sebagai salah satu bentuk media massa, film dinilai dapat mempengaruhi penontonnya. Film dipandang memiliki realisme, pengaruh emosional, dan popularitas yang lebih. Seiring berkembangnya waktu, film pun dimanfaatkan sebagai alat propaganda. Fenomena film sebagai alat propaganda mampu menyebabkan terjadinya krisis sosial di beberapa negara. Rasisme adalah permasalahan universal yang dipengaruhi oleh banyak faktor dari sosial, politik, historis dan ekonomi. Dari sejak dulu, banyak sekali kejadian - kejadian rasis di sekitar kita karena perbedaan warna kulit, suku, agama, ras dan budaya. Hingga saat ini pun, masih banyak kejadian yang mengarah kepada rasisme. Banyak sekali film-film yang mengangkat isu rasisme seperti The Help, Glory Road, Selma, The Butler, 12 Years A Slave dan masih banyak lagi masing-masing memiliki cara yang berbeda dalam mengakat isu rasisme. Penggambaran rasisme dapat juga dilihat di film Get Out.
Film Get Out yang disutradarai oleh Jordan Peele menceritakan seorang AfrikaAmerika yang mendapatkan perlakuan yang tidak menyenangkan dan diskriminasi dari orang berkulit putih. Film ini mendapatkan rating 99\% dari Rotten Tomatoes dan 77/10 dari $I M D B$. Film yang hadir pada bulan Maret 2017 ini, mengangkat isu rasisme dengan dibalut genre horror dan thriller. Film ini menggambarkan bagaimana fenomena orang kulit hitam terhadap perlakuan diskriminasi yang sering dilakukan diluar negeri sana dengan cara yang lebih modern. Selan itu, film ini juga menggambarkan perjuangan orang kulit hitam yang ingin terlepas dari perlakuan diskriminasi dari orang kulit putih.

Dalam penelitian ini, menggunakan beberapa penelitian terdahulu untuk dijadikan sebagai acuan. Dua diantaranya adalah penelitian skripsi dengan judul "Resepsi Film Habibie \& Ainun (Studi Tentang Resepsi Khalayak Terhadap Nilai-Nilai Kasih Sayang Dalam Keluarga Yang Direpresentasikan Dalam Film Habibie \& Ainun (2012)" yang 
ditulis oleh Yovita Rimbawati pada tahun 2013. Hasil yang didapat adalah Film Habibie dan Ainun merupakan salah satu film yang merepresentasikan nilai positif dalam keluarga. Film ini pun dinilai ringan dan mudah dimengerti oleh peminatnya. Film Habibie dan Ainun juga memberikan dampak psikologis yang dirasakan oleh penonton setelah menonton film ini. Yang membedakan dengan penelitian ini adalah objek penelitiannya merupakan film Habibie dan Ainun. Kemudian jurnal internasional dengan judul "Cultural Reception and Production: The Social Construction of Meaning in Book Clubs" ditulis oleh C.Clayton and Noah E. pada tahun 2012. Hasil yang didapat adalah Seluruh informan berada pada posisi dominan dan negosiasi. Komunikasi interpersonal satu anggota dengan anggota dapat mempengaruhi pendapat dan pemikiran seorang anggota terhadap buku yang dibaca. Yang membedakan dari penelitian ini adalah penggunaan subjek penelitiannya adalah pembaca buku novel yang bertema ras dan gender. Dengan melihat dari kedua penelitian sebelumnya, menjelaskan bahwa pembacaan makna khalayak terhadap informasi yang didapat dari media berbeda-beda. Dengan menggunakan film Get Out yang berlatar rasialisme sudah menjadi sebuah budaya di luar negeri, ingin menguji kembali berdasarkan budaya dan karakteristik di Indonesia terhadap menghadapi sebuah perbedaan yang dimiliki orang lain.

Maka dari itu memiliki ketertarikan untuk meneliti film Get Out karena penggambaran rasis dan penggambaran orang kulit hitam dalam film ini. Dalam penelitian ini, akan melihat bagaimana cara audiens memaknai nilai-nilai rasisme dalam film ini. Penonton sebagai audiens aktif dan bertindak juga sebagai penghasil makna. Bagaimana respon, penerimaan, dan tanggapan terhadap nilai-nilai rasisme yang diangkat dalam film Get Out. Untuk menganalisis persepsi penonton film Get Out terhadap rasisme yang ditunjukkan dalam film, akan menggunakan metode analisis resepsi encoding-decoding Stuart Hall. Penelitian akan menggunakan analisis resepsi dengan menggunakan encoding-decoding Stuart Hall karena teori ini berfokus kepada penerimaan khalayak terhadap informasi dari media.

\section{KAJIAN PUSTAKA}

\section{Komunikasi Massa}

Komunikasi massa merupakan salah satu proses komunikasi yang berlangsung pada peringkat masyarakat luas, yang identifikasinya ditentukan oleh ciri khas institusionalnya (gabungan antara tujuan, organisasi, dan kegiatan yang sebenarnya). Komunikasi massa mungkin lebih banyak melibatkan orang untuk waktu yang lebih banyak pula meskipun intensitasnya lebih rendah. Komunikasi massa bersifat komprehensif, maka komunikasi masssa pun melibatkan gagasan yang berkenan dengan setiap proses. Para individu menerima dan menangani banyak informasi secara langsung dari media massa (Mcquail, 1989:7).

Gerbner (2004: 15; dalam Ardianto, 2004:4) mengemukakan bahwa Mass communication is the technologically and institutionally based production and distribution of the most broadly shared continuous flow of messages in industrial societies (komunikasi massa adalah produksi dan distribusi yang berlandaskan teknologi dan lembaga dari arus pesan yang berkesinambungan serta paling luas dimiliki orang dalam masyarakat industri).

\section{Film sebagai Media Komunikasi Massa}

Seiring perkembangan teknologi komunikasi dan informasi, proses komunikasi dilakukan tidak hanya langsung (face to face, interpersonal) namun telah menggunakan media. Seperti media nirmassa dan media massa. Media nirmassa adalah media yang digunakan untuk menyampaikan informasi dengan sasaran tunggal seperti telepon, surat dan faks. Sedangkan media massa adalah media yang digunakan untuk menyampaikan informasi dengan sasaran luas dan area seluasluasnya. Media massa terdiri dari media cetak dan media elektronik, media cetak contohnya adalah surat kabar dan majalah sedangkan media elektronik contohnya adalah radio, televisi dan film.

Film adalah suatu media komunikasi massa yang sangat penting untuk mengkomunikasikan tentang suatu realita yang terjadi dalam kehidupan sehari - hari, Film memiliki realitas yang kuat salah satunya menceritakan tentang realitas masyarakat. Film diartikan sebagai hasil budaya dan alat ekspresi kesenian. (Effendy 1986:239) Film sebagai komunikasi massa merupakan 
gabungan dari berbagai tekhnologi seperti fotografi dan rekaman suara, kesenian baik seni rupa dan seni teater sastra dan arsitektur serta seni musik.

\section{Ras dan Stereotype}

Istilah ras digunakan untuk mendefinisikan orang berdasarkan persepsi perbedaan fisik yang menyiratkan perbedaan-perbedaan genetik. Meskipun kajian Antropologi menekankan bahwa ras bukan kategori natural, namun ras telah menjadi fakta sosial dan budaya dan hal ini digunakan unuk membenarkan kebijakan dan diskriminasi dan memengaruhi kehidupan, baik ras mayoritas maupun ras minoritas (Storey, 2008:241)

Rasisme mempunyai dua jenis yaitu (Neubeck, 2001:86):

\section{a. Personal Racism}

Personal Racism terjadi ketika individu mempunyai sikap curiga dan/atau terlibat dalam perilaku diskriminatif dan sejenisnya. Indikasi personal racism yaitu cara pandang individu (stereotip) atas dasar dugaan perbedaan ras, menghina referensi dan nama, perlakuan diskriminatif selama melakukan kontak interpersonal, tindak kekerasan, dan ancaman terhadap anggota kelompok minoritas yang diduga menjadi ras inferior.

b. Institutional Racism

Rasisme kelembagaan melibatkan perlakuan yang diberikan khusus untuk masyarakat minoritas di tangan lembaga tersebut. Institutional Racism menarik perhatian pada fakta bahwa kelompok-kelompok seperti penduduk asli Amerika, Afrika Amerika, Latino-Amerika, dan Asia Amerika sering menemukan diri mereka menjadi korban rutin kerja struktur organisasi tersebut. Tidak seperti beberapa bentuk Personal Racism, rasisme yang terjadi melalui operasi sehari-hari dan tahun ke tahun dari lembaga berskala besar.

Banyak pengalaman rasis yang terangterangan terjadi dalam interaksi antar-ras. Hampir setengah dari sampel probabilitas nasional orang dewasa kulit hitam melaporkan pada tahun 2000 bahwa mereka telah mengalami diskriminasi dalam 30 hari sebelumnya (T.W. Smith, 2000 dalam Fox, 2003:120). Orang hitam yang di kelas tengah sering mendapatkan perilaku yang tidak sopan di restoran, taksi yang kosong tidak mau berhenti, dan pegawai toko yang mencurigai mereka sebagai pencuri. Contoh yang lebih mengancam adalah polisi yang melakukan profil rasial seperti tiba-tiba mobil diberhentikan karena orang hitam mengemudi.

Rasisme dapat dianggap sebagai praktik yang dengan sengaja atau tidak, mengecualikan minoritas 'rasial' atau 'etis' dari menikmati hak, tanggung jawab dan tanggung jawab penuh yang tersedia bagi mayoritas penduduk.

\section{Reception Theory}

Resepsi berasal dari bahasa latin yaitu recipere, reception (Inggris) yang dapat diartikan sebagai penyambutan atau penerimaan pembaca. Resepsi dengan pengertian secara luas yaitu, cara-cara pemberian makna dan pengolahan teks terhadap tayangan televisi, sehingga memberikan respon terhadapnya. Teori resepsi (pemaknaan pembaca) memfokuskan kepada bagaimana pembaca atau khalayak dalam menerima pesan, bukan pada pengirim pesan. Pemaknaan pesan bergantung pada latar belakang budaya dan pengalaman hidup khalayak itu sendiri.

Riset khalayak menurut Stuart Hall (1973:180 dalam Baran, 2003:269-270) mempunyai perhatian langsung terhadap : (a) Analisis dalam konteks sosial dan politik dimana isi media diproduksi (encoding) ; dan (b) konsumsi isi media (decoding) da;am konteks kehidupan sehari - hari. Analisis resepsi memfokuskan pada perhatian individu dalam proses komunikasi massa (decoding), yaitu pada proses pemaknaan dan pemahaman yang mendalam atas media texts, dan bagaimana individu menginterpretasikan isi media.

Menurut Stuart Hall (1980:128), khalayak melakukan decoding terhadap pesan media melalui tiga kemungkinan posisi, yaitu: posisi hegemoni dominan, negosiasi, dan oposisi.

\section{Posisi Hegemoni Dominan}

Hegemoni Dominan sebagai situasi dimana "the media produce the message; the masses consume it. The audience reading coincide with the preferred reading" (media menyampaikan pesan, khalayak menerimanya. Apa yang disampaikan media secara kebetulan juga disukai oleh khalayak). Sebuah situasi yang dimana media menyampaikan pesan dengan menggunakan kode budaya dominan dalam masyarakat. 


\section{Posisi Negosiasi}

Posisi negosiasi adalah posisi dimana khalayak menerima ideologi dominan namun menolak penerapannya dalam kasus-kasus tertentu. Dalam hal ini, khalayak bersedia menerima ideologi dominan yang bersifat umum, namun mereka akan melakukan beberapa pengecualian dalam penerapannya yang disesuaikan dengan aturan budaya setempat.

\section{Posisi Oposisi}

Cara terakhir yang dilakukan khalayak dalam melakukan decoding terhadap pesan media adalah melalui oposisi yang terjadi ketika khalayak audiensi yang kritis mengganti atau mengubah pesan atau kode yang disampaikan media dengan pesan atau kode alternatif. Audiensi menolak makna pesan yang dimaksudkan atau disukai media dan menggantikannya dengan cara berpikir mereka sendiri terhadap topik yang disampaikan media.

\section{METODE PENELITIAN}

Metode penelitian yang digunakan dalam penelitian ini adalah metode penelitian kualitatif. Penelitian kualitatif adalah penelitian yang bermaksud untuk memahami fenonema tentang apa yang dialami oleh subjek penelitian misalnya perilaku, persepsi, motivasi, tindakan secara holistic dan dengan cara deskripsi dalam bentuk kata-kata dan bahasa pada suatu konteks khusus yang alamiah (Moleong, 2016:6).

Penelitian ini menggunakan metode penelitian kualitatif deskriptif dengan menggunakan analisis resepsi Stuart Hall. Analisis resepsi khalayak atau audiens memahami proses pembuatan makna yang dilakukan oleh audiens ketika mengonsumsi tayangan suatu media. Analisis resepsi mencoba memberikan sebuah makna atas pemahaman teks media (cetak, elektronik, internet) dengan memahami bagaimana karakter teks media dibaca oleh khalayak. Individu yang menganalisis media melalui kajian reception memfokuskan pada pengalaman dan pemirsaan khalayak (penonton/pembaca), serta bagaimana makna diciptakan melalui pengalaman tersebut. Stuart Hall mengemukakan bahwa makna yang dimaksudkan dan diartikan dalam sebuah pesan bisa terdapat perbedaan. Kode yang digunakan atau yang disandi (encode) dan yang disandi balik (decode) tidak selamanya berbentuk simetris.. Ketika audiens menyandi balik (decoding) dalam suatu komunikasi, maka terdapat posisi hipotekal, yakni : (1) Dominant-Hegemonic Positio n, (2) Negotiated Position, (3) Oppositional Position.

Subjek penelitian yang digunakan adalah informan yang dipilih berdasarkan kriteria-kriteria tertentu. Kriterianya adalah yang pernah menonton film Get Out lebih dari satu kali, hanya memiliki ketertarikan menonton film dengan genre horror ataupun thriller. Objek penelitian pada penelitian ini adalah tujuh scene rasisme dalam film Get Out. Film ini disutradarai oleh Jordan Peele dan diproduseri oleh Sean McKittrick, Jason Blum, Edward H. Hamm Jr. dan Jordan Peele. Film Get Out ditayangkan perdana di Festival Film Sundance pada 24 Januari 2017 dan dirilis di Amerika Serikat pada 24 Februari 2017. Untuk di Indonesia sendiri, film ini tayang di bioskop pada 29 Maret 2017.

Dalam melakukan wawancara, penelitian ini menggunakan panduan wawancara yang terdiri dari pertanyaanpertanyaan akan ditanyakan kepada informan. Pertanyaan terdiri dari 18 pertanyaan yang mewakilkan hasil tiga pembacaan posisi khalayak menurut Stuart Hall, pemaknaan resepsi, dan hal-hal yang diperlukan untuk penelitian ini.

Unit analisis merupakan fokus-fokus penelitian dari input, analisis dan sub analisis. Fokus dalam penelitian ini adalah konten rasisme yang ada pada tayangan film Get Out. Input yang digunakan dalam unit analisis adalah konten rasisme dalam film Get Out. Analisis yang digunakan dalam unit analisis adalah reception theory oleh Stuart Hall. Sub analisis yang digunakan adalah Dominant position, Negotiated position dan Oppositional position.

Jenis sumber data yang digunakan dalam penelitian ini adalah terdiri dari data primer dan data sekunder. Data primer yang digunakan adalah pada saat melakukan wawancara mendalam dengan informan film Get Out. Data sekunder merupakan data tambahan untuk pelengkap untuk menyempurnakan penelitian ini diambil dari hasil pengumpulan dengan berbagai sumber data yang sesuai dengan topik penelitian yang dipilih, diantaranya adalah beberapa buku, dokumentasi teks film dan artikel-artikel dari media online yang berhubungan dengan penelitian ini. Teknik pengumpulan data yang 
digunakan dalam penelitian ini menurut Prastowo (2011:211) yaitu sebagai berikut:

a. Wawancara Mendalam (in-depth interviewing): Teknik pengumpulan data dengan melakukan wawancara mendalam. Cara ini dilakukan untuk menggali informasi dari responden dan mendapatkan kejujuran dalam menyampaikan informasi yang sebenarnya.

b. Data Dokumentasi: Data dokumentasi merupakan data pendukung sebagai penguat data hasil observasi dan wawancara. Ketika seorang peneliti mengemas sebuah laporan penelitiannya melaui proses triangulasi ketiga data yang dihimpun melalui observasi, wawancara, dan dokumentasi harus saling menguatkan satu dengan yang lainnya.

c. Studi Pustaka

Teknik triangulasi yang digunakan pada penelitian ini adalah dengan triangulasi sumber, triangulasi teknik, dan triangulasi teori sesuai dengan Moleong (2006:330-331). Triangulasi sumber yaitu teknik pemeriksaan keabsahan data dengan cara membandingkan data yang diperoleh dari narasumber. Triangulasi teknik dilakukan dengan membandingkan data yang dihasilkan dari beberapa teknik yang berbeda yang digunakan dalam penelitian. Triangulasi Teori yaitu membandingkan beberapa teori yang terkait dengan penelitian. Selanjutnya akan ditambah kembali data melalui dokumentasi mulai dari jurnal, artikel, maupun buku-buku yang berkaitan. Tahapan proses analisis data, yang akan digunakan dalam penelitian ini sesuai menurut Miles dan Huberman yaitu dengan melakukan pengumpulan data, melakukan reduksi data, melakukan display data dan menarik kesimpulan.

\section{HASIL DAN PEMBAHASAN}

Tahapan pertama dari analisis penelitian ini adalah menganalisis data kemudian menginterpretasikan dari hasil wawancara yang dilakukan secara mendalam sebelumnya, pada penelitian resepsi ini tidak ada pembedaan yang khusus antara analisis dan interpretasi khalayak mengenai pengalaman media mereka. Setelah itu data hasil dari wawancara tersebut dibuat transkrip, kemudian dikategorisasikan berdasarkan tematema yang muncul pada pemaknaan yang dilakukan dari subjek penelitian. Tahapan kedua yaitu tema-tema yang muncul kemudian dianalisis dengan mempertimbangkan proses pemaknaan, karakteristik individu, cara pemaknaan, sekaligus juga konteks sosial dan kultural yang melingkupi proses pemaknaan. Pada bagian ini tidak hanya analisis dari wawancara tetapi juga studi diakronik dengan menggunakan prinsip interteks dari analisis wacana, di mana wacana dari khalayak diinterpretasikan dengan mempertimbangkan konteks baik itu wacana teks media maupun konteks sosial, dan kondisi psokologis dari khalayak. Tahapan ketiga adalah tema-tema yang muncul kemudian dikelompokkan ke dalam tiga kelompok pemaknaan; dominant position, negotiated position, dan oppositional position.

\section{Informan 1}

Pada adegan pertama dalam Film Get Out, informan satu berpendapat bahwa tidak seharusnya polisi bersikap seperti itu kepada penumpang berkulit hitam. Dalam adegan kedua, informan berpendapat bahwa perbincangan yang terjadi merupakan hal yang biasa saja namun sebaiknya memilih topik lain. Dalam adegan ketiga, informan berpendapat bahwa tidak seharusnya dia bersikap memandang rendah dan berbicara orang yang berkulit hitam memiliki badan yang besar mengerikan. Dalam adegan keempat, informan berpendapat bahwa tidak seharusnya mendapat perlakuan untuk membandingkan fisik orang kulit hitam dengan orang kulit putih. Dalam adegan kelima, informan berpendapat bahwa tidak seharusnya dirinya mendapat perlakuan untuk membandingkan fisik yang berbeda dengan orang berkulit putih. Dalam adegan keenam, informan berpendapat bahwa tidak seharusnya berkata orang berkulit hitam itu keren. Adegan ketujuh, informan berpendapat bahwa percakapan yang terjadi merupakan hal yang biasa karena pertanyaan tersebut hanya berasal dari rasa penasaran saja. Dengan demikian informan satu berada pada tipe pembacaan oppositional reading karena pendapat yang dikemukakannya tersebut tidak menyetujui terhadap makna rasisme yang digambarkan dalam film Get Out.

\section{Informan 2}

Pada adegan pertama dalam Film Get Out, informan dua berpendapat bahwa tidak seharusnya polisi bersikap seperti itu kepada 
penumpang berkulit hitam. Dalam adegan kedua, informan berpendapat bahwa percakapan yang terjadi adalah hal yang wajar. Dalam adegan ketiga, informan berpendapat bahwa hal yang dilakukan hanyalah memuji bentuk tubuh yang dimiliki oleh pemeran utama dalam film. Dalam adegan keempat, informan berpendapat bahwa hal yang terjadi adalah sangat wajar. Dalam adegan kelima, informan berpendapat pembicaraan mengarah kepada memberikan pujian kepada pemeran utama karena bentuk tubuh yang dimilikinya. Dalam adegan keenam, informan berpendapat bahwa memberitahukan warna hitam tren menjelaskan bahwa pemeran utama diterima dalam acara tersebut. Adegan ketujuh, informan berpendapat bahwa pertanyaan yang diajukan semata-mata karena rasa penasaran.

Dengan demikian informan satu berada pada tipe pembacaan hegemony dominant reading karena pendapat yang dikemukakannya tersebut tidak menyetujui terhadap makna rasisme yang digambarkan dalam film Get Out.

\section{Informan 3}

Pada adegan pertama dalam Film Get Out, informan tiga berpendapat bahwa apa yag dilakukan polisi merupakan hal yang tidak wajar. Dalam adegan kedua, informan berpendapat bahwa perbincangan tersebut membuat tidak nyaman pemeran utama sehingga tidak menyetujui adegan tersebut. Dalam adegan ketiga, informan berpendapat bahwa rasis terlihat karena warna kulit yang dimiliki oleh pemeran utama. Dalam adegan keempat, informan berpendapat bahwa tidak seharusnya mendapat perlakuan untuk membandingkan fisik orang kulit hitam dengan orang kulit putih. Dalam adegan kelima, informan berpendapat bahwa tidak seharusnya pemeran utama mendapatkan perlakuan seperti yang ditujukan dalam adegan. Dalam adegan keenam, informan berpendapat bahwa tidak seharusnya berkata orang berkulit hitam itu keren. Adegan ketujuh, informan berpendapat bahwa tidak seharusnya bertanya menanyakan apakah memiliki warna kulit hitam menjadi sebuah keuntungan atau kerugian. Dengan demikian informan satu berada pada tipe pembacaan oppositional reading karena pendapat yang dikemukakannya tersebut tidak menyetujui terhadap makna rasisme yang digambarkan dalam film Get Out.

\section{Informan 4}

Pada adegan pertama dalam Film Get Out, informan empat berpendapat bahwa apa yag dilakukan polisi merupakan hal yang tidak wajar dan tidak seharusnya dilakukan. Dalam adegan kedua, informan berpendapat bahwa perbincangan yang terjadi membuat suasana menjadi tidak nyaman dan menganggu lawan bicara karena membicarakan perbedaan warna kulit. Dalam adegan ketiga, informan berpendapat bahwa tidak seharusnya dia membicarakan bahwa orang berkulit hitam pasti memiliki badan yang besar dan menyeramkan. Dalam adegan keempat, informan berpendapat bahwa tidak seharusnya mendapat perlakuan untuk membandingkan fisik orang kulit hitam dengan orang kulit putih. Dalam adegan kelima, informan berpendapat bahwa tidak seharusnya dirinya mendapat perlakuan untuk membandingkan fisik yang berbeda dengan orang berkulit putih. Dalam adegan keenam, informan berpendapat bahwa tidak seharusnya berkata orang berkulit hitam itu keren. Adegan ketujuh, informan berpendapat bahwa tidak seharusnya bertanya menanyakan apakah memiliki warna kulit hitam menjadi sebuah keuntungan atau kerugian.

Dengan demikian informan satu berada pada tipe pembacaan oppositional reading karena pendapat yang dikemukakannya tersebut tidak menyetujui terhadap makna rasisme yang digambarkan dalam film Get Out.

\section{Tabel 1 Pengelompokkan Informan Berdasarkan Tiga Posisi Penonton}

\begin{tabular}{|c|c|c|c|c|}
\hline No. & $\begin{array}{l}\text { Scene } \\
\text { Rasisme }\end{array}$ & $\begin{array}{l}\text { Dominant } \\
\text { Position }\end{array}$ & $\begin{array}{l}\text { Negotiated } \\
\text { Position }\end{array}$ & Oppositional Position \\
\hline 1 & Scene 1 & Informan 3 & Tidak ada & $\begin{array}{l}\text { Informan } 1 \text {, informan } 2 \\
\text { dan informan } 4\end{array}$ \\
\hline 2 & Scene 2 & Informan 2 & Tidak Ada & $\begin{array}{l}\text { Informan } 1 \text {, informan } 3 \text {, } \\
\text { dan informan } 4\end{array}$ \\
\hline 3 & Scene 3 & Tidak Ada & Tidak ada & $\begin{array}{l}\text { Informan } 1 \text {, informan } 2 \text {, } \\
\text { informan } 3 \text {, dan informan } \\
4\end{array}$ \\
\hline 4 & Scene 4 & Informan 2 & Tidak ada & $\begin{array}{l}\text { Informan } 1 \text {, informan } 3 \text {, } \\
\text { dan informan } 4\end{array}$ \\
\hline 5 & Scene 5 & Informan 2 & Tidak ada & $\begin{array}{l}\text { Informan } 1 \text {, informan } 3 \text {, } \\
\text { dan informan } 4 \text {. }\end{array}$ \\
\hline 6 & Scene 6 & Tidak ada & Tidak ada & $\begin{array}{l}\text { Informan } 1 \text {, informan } 2 \text {, } \\
\text { informan } 3 \text {, dan informan } \\
4 \text {. }\end{array}$ \\
\hline 7 & Scene 7 & Informan 2 & Tidak Ada & $\begin{array}{l}\text { Informan } 1 \text {, informan } 3 \text {, } \\
\text { dan informan } 4 .\end{array}$ \\
\hline
\end{tabular}

Sumber: Data terolah 


\section{KESIMPULAN DAN SARAN \\ Kesimpulan}

Berdasarkan dari hasil penelitian yang peneliti lakukan melalui wawancara mendalam dan observasi mengenai pembacaan (resepsi) khalayak tentang pemaknaan rasisme dalam film Get Out bahwa posisi penonton dalam penerimaan mereka tentang makna rasisme dalam film Get Out didominasi oleh posisi oppositional position. Dari ketujuh adegan unit analisis yang diteliti, lima diantaranya berada di oppositional position mutlak dalam satu scene lainnya informan lain berada di posisi dominant position. Yang dimana dalam setiap adegan menampilkan materi rasisme yang berbeda-beda.

\section{Saran}

Berdasarkan kesimpulan yang telah disampaikan sebelumnya, selanjutnya peneliti akan memberikan saran-saran sebagai berikut:

1. Saran Akademis

Disarankan untuk peneliti selanjutnya, dapat menggunakan objek yang lain seperti televisi, koran ataupun media lainnya yang ada.

2. Saran Praktis

Diharapkan untuk penonton film ini tidak menjadikan film ini sebagai contoh dalam kehidupan sehari-hari dan menjadikan film ini sebagai hiburan semata. Disarankan juga untuk memilih-milih tontonan film yang mana dapat dijadikan contoh dalam kehidupan sehari-hari.

\section{REFERENSI}

Ardianto, E. (2004). Komunikasi massa suatu pengantar. Bandung: Simbiosa Rekatama Media.

Baran, S. J. (2003). Introduction to mass communication and media; media literacy and culture: Third edition, America: MC Graw Hill

Effendy, O. U. (1986). Televisi siaran, teori dan praktek. Bandung: Alumni.

Fox, C. (2003). Race, racism, and discrimination: bridging problems, method, and theory in social psychological research. American Sociological Association.

Hall, S. (1980). Encoding/decoding. In D.H Stuart Hall (Ed.), Culture, Media, Language. New York : Routledge,128138.
McQuail, D. (1989). Teori komunikasi massa :suatu pengantar/Denis McQuail. Dharma, Agus (Penerjemah). Jakarta: Erlangga

McQuail, D. (2011). Teori komunikasi massa. Jakarta: Salemba Humanika.

Moleong, L. J. (2006). Metodologi penelitian kualitatif. Bandung: Rosdakarya. Cetakan kedua puluh.

Moleong, L. J. (2016). Metodologi penelitian kualitatif (Edisi Revisi). Bandung: Remaja Rosdakarya.

Mulyana, D. (2000). Ilmu komunikasi suatu pengantar. Bandung: PT Remaja Rosdakarya

Neubeck, K. J. W. (2011). Racism: playing the race card against america's poor. New York: Routledge

Prastowo, A. (2011). Metode penelitian kualitatif dalam perspektif rancangan penelitian. Jogjakarta: Ar-Ruzz Media.

Rakhmat, J. (1991). Metode penelitian komunikasi. Bandung: PT Remaja Rosdakarya.

Storey, J. (2008). Cultural theory and popular culture: an introduction. Fifth Edition. New York.

Wiryanto. (2008). Pengantar ilmu komunikasi. Jakarta: Grasindo. 
Jurnal Manajemen Maranatha ø Vol. 18 Nomor 2, Mei (2019) 